\title{
Zein Microneedles for Transcutaneous Vaccine Delivery: Fabrication, Characterization, and in Vivo Evaluation Using Ovalbumin as the Model Antigen
}

\author{
Shubhmita Bhatnagar, Sumeet Rajesh Chawla, ${ }^{\dagger}$ Onkar Prakash Kulkarni, \\ and Venkata Vamsi Krishna Venuganti*ie
}

Department of Pharmacy, Birla Institute of Technology and Science (BITS) Pilani, Hyderabad Campus, Shameerpet, Hyderabad 500078, Telangana, India

Supporting Information

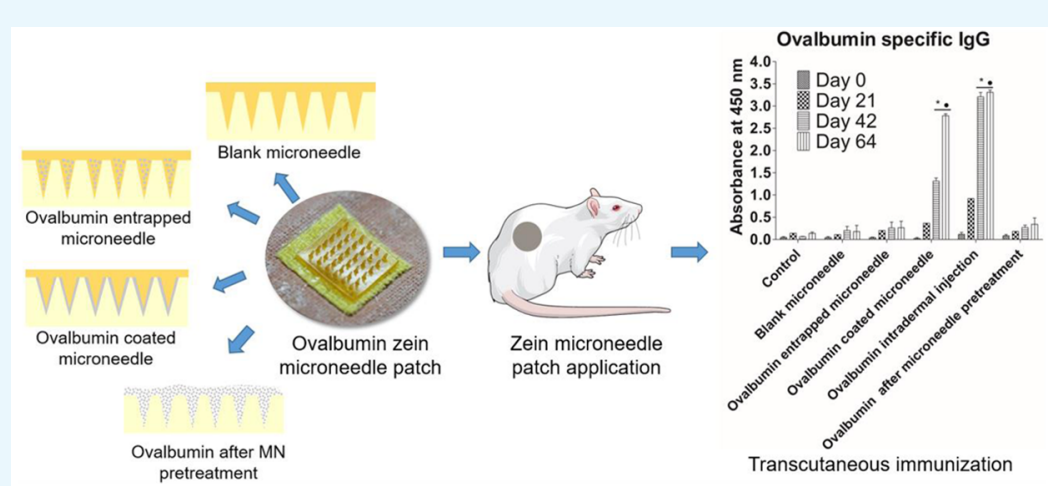

ABSTRACT: Transcutaneous antigen administration provides an alternative to invasive syringe injections. The objective of this study was to investigate the feasibility of fabrication and antigen delivery using microneedles made from corn protein, zein. Micromolding technique was used to cast cone-shaped zein microneedles (ZMNs). The insertion of ZMNs and the delivery of the model antigen, ovalbumin (OVA), into the skin was confirmed by histological examination and confocal microscopy. In addition, a significantly $(p<0.05)$ lower bacterial skin penetration was observed after ZMN application compared with hypodermic syringe application. OVA coated on ZMNs was stable after storage under ambient and refrigerator conditions. Transcutaneous immunization studies showed significantly $(p<0.001)$ greater antibody titers (total $\operatorname{IgG}, \operatorname{IgG} 1$, and IgG2a) after the application of OVA-coated ZMNs and OVA intradermal injection compared with the control group. Taken together, antigencoated ZMNs can be developed for transcutaneous vaccine delivery.

\section{INTRODUCTION}

Currently, majority of the vaccines are administered using hypodermic needles. The syringe-based injections have been associated with multiple disadvantages including needle phobia, needle injuries, usage of contaminated needles, and requirement of a healthcare professional among others. ${ }^{1-3}$ Recent dramatic improvements in precision engineering have allowed for the design and fabrication of micron-scale devices that can be used to deliver vaccines. ${ }^{4}$ There has been a tremendous interest in the development of microneedle devices for transcutaneous therapeutic and vaccine delivery and for cosmetic applications. ${ }^{5,6}$ This has led to the publication of many research reports and the commercial approval of few microneedle-based devices. ${ }^{7}$ The approved devices include Intanza to deliver influenza vaccine and Dermaroller for cosmetic skin application. Furthermore, multiple microneedlebased transcutaneous delivery systems are under various phases of clinical studies. ${ }^{8}$

The major advantage associated with microneedle-based devices over hypodermic syringes include minimal invasion inside of the skin membrane, thereby reducing needle injuries and improving user compliance. ${ }^{9}$ More recently, it has been understood that multiple factors influence the utilization of microneedles for transcutaneous immunization. In addition to the needle size, shape, aspect ratio, and distance of separation between the needles, the material of construction has been found to be an important contributor to antigen loading, skin insertion, antigen release, and stability of the antigen. ${ }^{10}$ Therefore, the initial microneedles made of stainless steel, silica, and ceramic gave way to the development of microneedles made of biocompatible polymeric materials. ${ }^{11}$ These biocompatible polymeric microneedles are made of polylactide-co-glycolide, poly-L-lysine, carboxymethyl cellulose, sodium alginate, chitosan, polyvinyl pyrrolidone, and polyvinyl alcohol. ${ }^{12}$ Most of these microneedle patches are prepared using a simple micromolding technique. ${ }^{13,14}$ However, the

Received: March 22, 2017

Accepted: March 27, 2017

Published: April 6, 2017 

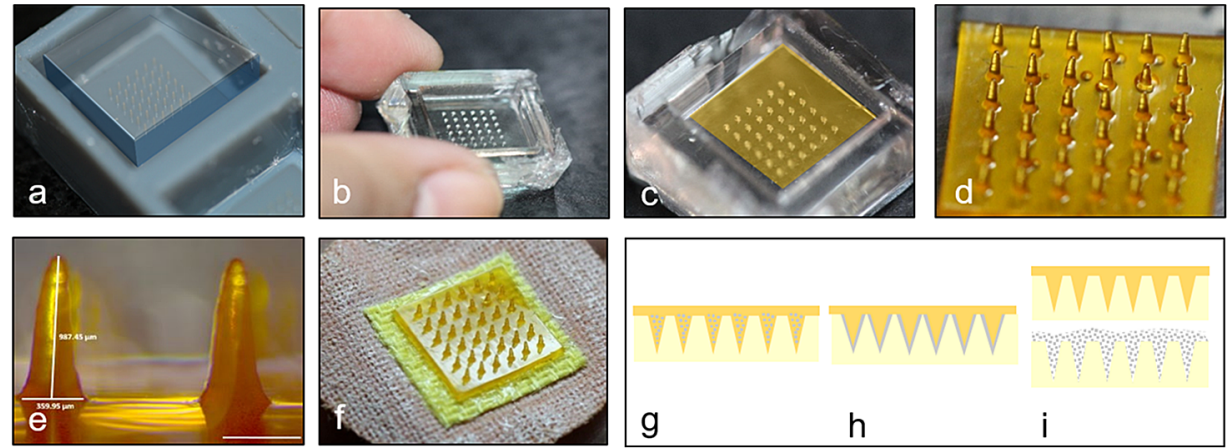

Figure 1. Fabrication of ZMNs: (a) Casting of PDMS mold from the 3D printed ABS mold; (b) PDMS mold; (c) solvent casting of ZMNs; (d) photograph of a $6 \times 6$ zein microneedle array; (e) micrograph of zein microneedles; and (f) microneedle array attached to an adhesive backing membrane for transcutaneous immunization. Schematic representation of (g) OVA-entrapped ZMNs, (h) OVA-coated ZMNs, and (i) OVA application after ZMN pretreatment. The scale bar in "e" represents $500 \mu \mathrm{m}$.
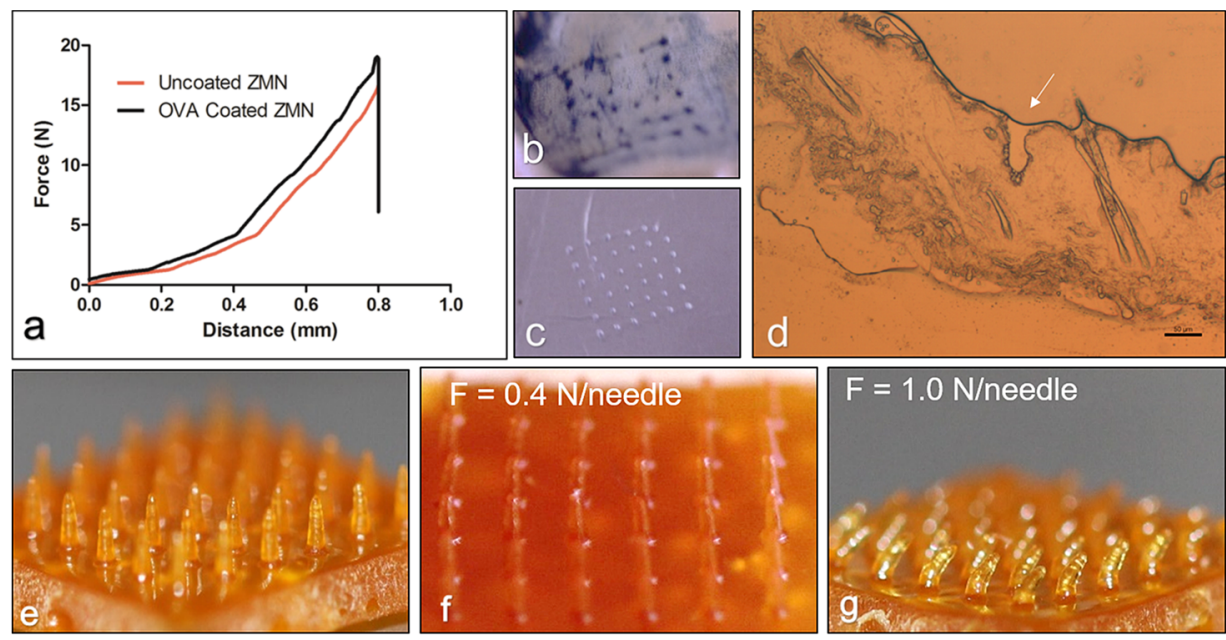

Figure 2. Mechanical strength of ZMNs. (a) Determination of the bending force for blank (uncoated) and OVA-coated ZMNs. Each plot represents the average of three experiments. $(b, c)$ Methylene blue-stained skin after ZMN insertion showing the pores created and the reciprocal images of the etching visible on the Parafilm placed under the skin. (d) Micrograph of skin cryosection after treating with ZMNs. The arrow indicates the pore created after ZMN insertion. The scale bar represents $50 \mu \mathrm{m}$. ZMNs before (e) and after insertion into the skin with a force of $0.4 \mathrm{~N} / \mathrm{needle}(\mathrm{f})$ and $1.0 \mathrm{~N} /$ needle $(\mathrm{g})$ using the texture analyzer. A pretest speed of $1 \mathrm{~mm} / \mathrm{s}$ and a test speed $0.5 \mathrm{~mm} / \mathrm{s}$ were used.

clinical development of polymer-based microneedles has been limited by the mechanical strength of the needles, antigen stability, and release characteristics.

To this end, here we report the fabrication of a microneedle array made of zein protein. Gorham in 1821 first described zein after isolating the protein from maize. ${ }^{15}$ Since then, numerous research papers have been published and many patents have been granted for better techniques of extraction of zein from maize. Zein is classified as a prolamin and is the alcohol-soluble protein of corn. ${ }^{16}$ Essentially, zein is a mixture of four proteins of different molecular sizes and solubility: $\alpha, \beta, \gamma$, and $\delta .{ }^{17} \alpha$ Zein accounts for $70 \%$ of the total content followed by $20 \%$ of $\gamma$-zein. Zein is insoluble in water alone and is soluble in binary solvents such as hydroalcoholic preparations. ${ }^{18}$

Zein has been used in the manufacture of biodegradable plastics, fibers, adhesives, coatings, inks, cosmetics, textiles, and chewing gum. ${ }^{19}$ Currently, film coating has been the most successful application of zein in the food and pharmaceutical industry. Zein being a protein itself is expected to have molecular interactions with protein-based active molecules and enhance their loading and delivery. Surprisingly, to the best of our knowledge, zein has never been used to prepare drug delivery devices including microneedles. Here, we report for the first time, microneedles made of zein for transcutaneous delivery of the model antigen, ovalbumin (OVA).

Zein microneedles (ZMNs) were prepared using the micromolding technique. The disadvantages associated with traditional microfabrication-based etching techniques, including high cost and difficult scale-up, can be overcome by using the micromolding technique. Micromolding technique requires a master mold that can be prepared using metal, silicon, or polymers such as acrylanitrile butadiene styrene (ABS) and a secondary mold prepared using polydimethylsiloxane (PDMS). This PDMS mold can be reused to make hundreds of polymeric microneedle arrays. Three-dimensional (3D) printing technique was used to prepare the ABS master mold. The ZMNs were evaluated for their feasibility to deliver OVA as a model antigen into the skin for transcutaneous immunization.

\section{RESULTS AND DISCUSSION}

Characterization of ZMNs. ZMNs were fabricated using the micromolding technique, where a poly-jet $3 \mathrm{D}$ printer was used to print the master mold. Recently, 3D printing has been used to print microstructures including microneedles. ${ }^{20}$ Only few polymeric materials can be fabricated into microstructures using the $3 \mathrm{D}$ printing technique. Hence, the $3 \mathrm{D}$ printing 
technique was used to produce master molds from ABS. These master molds were then used to prepare PDMS production molds that were used in casting. This micromolding technique is considered to be efficient because the master mold and the production mold can be reused to cast several microneedle arrays. Such a system can help in high volume manufacturing at low production costs. ${ }^{21,22}$

Figure 1 shows the scheme of fabrication of ZMNs. Figure 1d,e shows a solvent-casted ZMN array and a microscopic image of two microneedles, respectively. The needles are seen arranged in a $6 \times 6$ array within an area of $1 \mathrm{~cm}^{2}$. The needles are conical in shape with the average height and base width of $974.6 \pm 13.8$ and $362.7 \pm 13.8 \mu \mathrm{m}(n=10)$, respectively. The surface of the microneedles was smooth with no observable stress on the microneedle structures (Figure 1e).

Polymer microneedles need to have sufficient mechanical strength for penetration into the skin. It is expected that the needles do not bend or break during handling and skin insertion. Texture analysis showed a bending force of $16.09 \pm$ 1.52 and $19.20 \pm 1.75 \mathrm{~N}$ for blank and OVA-coated ZMNs, respectively $(n=3)$. The force-displacement curves showed no discontinuous point, indicating no needle failure (Figure 2a). The forces required for OVA-coated ZMNs were greater compared with those for uncoated ZMNs. In the absence of plasticizers, ZMNs showed significantly $(p<0.05)$ lower bending forces (Figure S3) and were observed to be brittle.

To study the required skin insertional force, the $\mathrm{ZMNs}$ were inserted into the excised mouse skin at 0.4 and $1 \mathrm{~N} /$ needle. Figure $2 \mathrm{~b}, \mathrm{c}$ shows pores created on the mouse skin and Parafilm with the application of $0.4 \mathrm{~N} /$ needle force. Figure $2 \mathrm{~d}$ shows the micrograph of the cryosectioned mouse skin with a single pore created after the insertion of ZMNs at $0.4 \mathrm{~N} /$ needle force. The needles did not bend or break with the application of $0.4 \mathrm{~N} /$ needle force (Figure 2f). On the other hand, Figure $2 \mathrm{~g}$ shows a bent ZMN upon the application of $1 \mathrm{~N} /$ needle force.

Zein has been widely studied for its film-forming properties. Zein films were found to be brittle in the absence of plasticizers. ${ }^{20}$ The flexibility of zein films improved with the addition of plasticizers. The effect of plasticizers including glycerol, triethylene glycol, dibutyl tartrate, levulinic acid, polyethylene glycol (PEG) 300, and oleic acid on the mechanical properties and moisture content of the films has been studied. Similarly, ZMNs without plasticizers showed a brittle behavior. The needle tips were broken with the application of $<0.4 \mathrm{~N} /$ needle force. Furthermore, the microneedle base plate cracked during handling and pressing onto the skin. To improve the strength of the microneedle array, glycerol and PEG 400 were incorporated as plasticizers in the polymer matrix. Both glycerol and PEG have previously been reported as compatible plasticizers with zein. ${ }^{20}$ Previous study showed that a force of $5 \mathrm{~N}$ was optimal for the efficient insertion of polyvinyl alcohol microneedles inside of the porcine skin. ${ }^{23}$ For ZMNs, only $0.4 \mathrm{~N} /$ needle was sufficient. The skin insertion force will depend on the shape, aspect ratio, needle-tip diameter, and distance of separation between the microneedles. Because polymer microneedles are weaker (smaller Young's modulus compared with that of metal microneedles), they need to have a wider base for additional mechanical strength. ZMNs were prepared with an aspect ratio of 2.64 with approximate tip radius and separation between microneedles of 30 and $1160 \mu \mathrm{m}$, respectively.

Insertion of OVA-Coated ZMNs into the Mouse Skin. Fluorescein isothiocyanate (FITC)-tagged OVA was used to visualize the OVA delivery inside of the skin. The absence of free FITC in the FITC-OVA conjugate was confirmed using thin layer chromatography (Figure S1). FITC conjugation was confirmed using Fourier transform infrared (FTIR) spectroscopic studies by the absence of a characteristic isothiocyanate stretching band at $2018 \mathrm{~cm}^{-1}$ and the appearance of thiourea bands at $1100-1500$ and $400-600 \mathrm{~cm}^{-1}$ wavenumbers (Figure S2). UV-visible (UV-vis) spectroscopy was used to determine the number of moles of FITC conjugated to $1 \mathrm{~mol}$ of OVA. It was found that $\lambda_{\max }$ of free FITC $(490 \mathrm{~nm})$ shifted to $495 \mathrm{~nm}$ wavelength after conjugation with OVA (Figure S1). UV-vis spectroscopic analysis showed $1.23 \mathrm{~mol}$ of FITC conjugated to 1 mol of OVA.

Figure 3a,b shows the fluorescence images of FITC-OVAcoated $\mathrm{ZMNs}$ before and after the insertion into the skin for 30
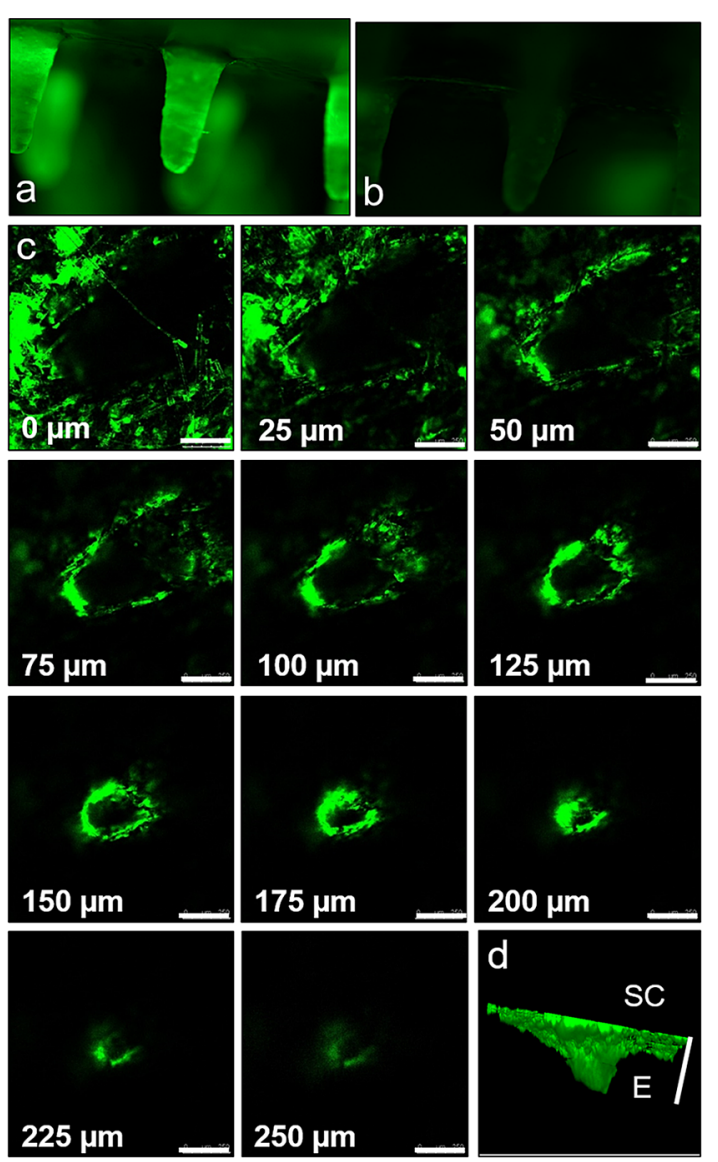

Figure 3. Fluorescence image of FITC-OVA-coated ZMNs before (a) and after (b) insertion into the skin for $30 \mathrm{~min}$. (c) Confocal micrographs of optical sections of the skin sample from the surface $(0$ $\mu \mathrm{m})$ to $250 \mu \mathrm{m}$ inside of the skin, and $3 \mathrm{D}$ representation of the microchannel created due to the insertion of FITC-OVA-coated ZMNs (d). Dark areas indicate lack of fluorescence. The scale bar represents $250 \mu \mathrm{m}$. SC, stratum corneum and E, epidermis.

min. Figure $3 \mathrm{a}$ shows the uniform coating of $\mathrm{ZMNs}$ with FITC-OVA. The intensity of fluorescence decreased after 30 min insertion of $\mathrm{ZMNs}$ inside of the skin (Figure $3 \mathrm{~b}$ ).

Figure $3 \mathrm{c}$ shows the confocal micrographs of the skin after 30 min insertion of FITC-OVA-coated ZMNs at varying depths. The series of micrographs show a single pore created by the microneedle insertion. The fluorescence associated with FITC-OVA was seen up to a depth of $250 \mu \mathrm{m}$ inside of the skin. Figure $3 \mathrm{~d}$ shows a reconstructed $3 \mathrm{D}$ image of the 

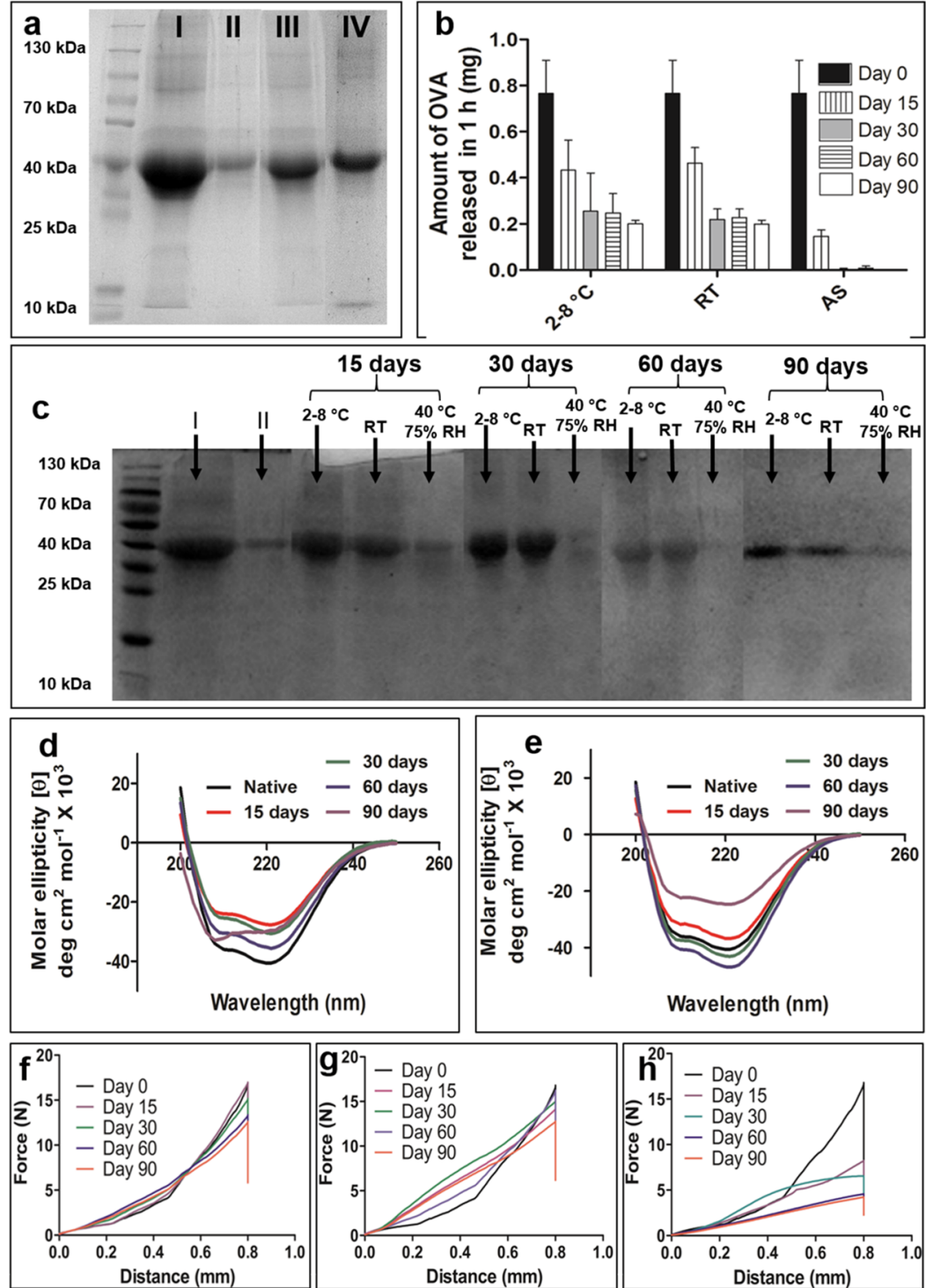

Figure 4. (a) SDS-PAGE analysis of OVA released from coated ZMNs. Lanes: I-OVA (20 $\mu \mathrm{g})$, II-OVA (2 $\mu \mathrm{g})$, III-OVA released from OVAcoated ZMNs in $1 \mathrm{~h}$, and IV-OVA release post ZMN insertion into the skin for $30 \mathrm{~min}$. (b) Amount of OVA released in $1 \mathrm{~h}$ from coated ZMNs stored under different storage conditions. (c) SDS-PAGE analysis of the stability of OVA released in $1 \mathrm{~h}$ from coated ZMNs. Lanes: I-OVA (20 $\mu \mathrm{g})$ and II-OVA $(2 \mu \mathrm{g})$. Far-UV circular dichroism (CD) spectra of OVA released from the coated ZMNs stored at $2-8{ }^{\circ} \mathrm{C}(\mathrm{d})$ and at room temperature (RT) (e). Force-displacement curves obtained using a texture analyzer for ZMNs stored at $2-8{ }^{\circ} \mathrm{C}(\mathrm{f})$, at $\mathrm{RT}(\mathrm{g})$, and at $40{ }^{\circ} \mathrm{C} / 75 \%$ relative humidity $(\mathrm{RH})(\mathrm{h})$ on different days. The results represent the average of three replicates. AS, accelerated storage $\left(40{ }^{\circ} \mathrm{C}, 75 \pm 5 \% \mathrm{RH}\right)$.

microchannel created within the skin. The pore can be seen tapering down from the stratum corneum to the epidermis. The results from confocal microscopy confirm that the fluorescence intensity lost from the microneedle surface after insertion into the skin can be attributed to the adsorption of FITC-OVA within the skin.

Skin Disposition of the OVA Delivered Using ZMNs. The amount of OVA entrapped or coated on ZMNs was measured using an indirect method. For all samples, the amount of OVA released from the ZMNs was determined after incubation in phosphate-buffered saline (PBS) for $1 \mathrm{~h}$. The amount of OVA released from the ZMNs entrapped with OVA was $0.088 \pm 0.014 \mathrm{mg}$ in $1 \mathrm{~h}$. On the other hand, $0.766 \pm 0.144$ mg of OVA was released from the ZMNs coated with OVA. The amount of OVA released from the microneedles that were previously inserted inside of the skin for $30 \mathrm{~min}$ was reduced to $0.124 \pm 0.018 \mathrm{mg}$.
Vitamin B-coated stainless steel microneedles showed a delivery efficiency of $90 \%$ in the excised pig skin. ${ }^{24}$ Similarly, influenza virus-coated stainless steel microneedles showed $70 \%$ delivery efficiency. ${ }^{25}$ Here, OVA-coated ZMNs showed a delivery efficiency of $85 \%$ in the excised mouse skin.

Stability of the OVA-Coated ZMNs. Sodium dodecyl sulfate polyacrylamide gel electrophoresis (SDS-PAGE) was performed for OVA samples released before and after the insertion of ZMNs into the skin. Figure 4a shows the bands for OVA released from the ZMNs. The single band at $43 \mathrm{kDa}$ shows that the OVA was intact after coating on ZMNs.

Figure $4 \mathrm{~b}$ shows the amount of OVA released from coated microneedles in $1 \mathrm{~h}$ after storage under different environmental conditions for up to 90 days. The amount of OVA released reduces with time under all storage conditions. The increase in the storage temperature from $2-8$ to $40{ }^{\circ} \mathrm{C}$ reduced the amount of OVA released from the ZMNs. Similarly, Figure $4 \mathrm{c}$ 

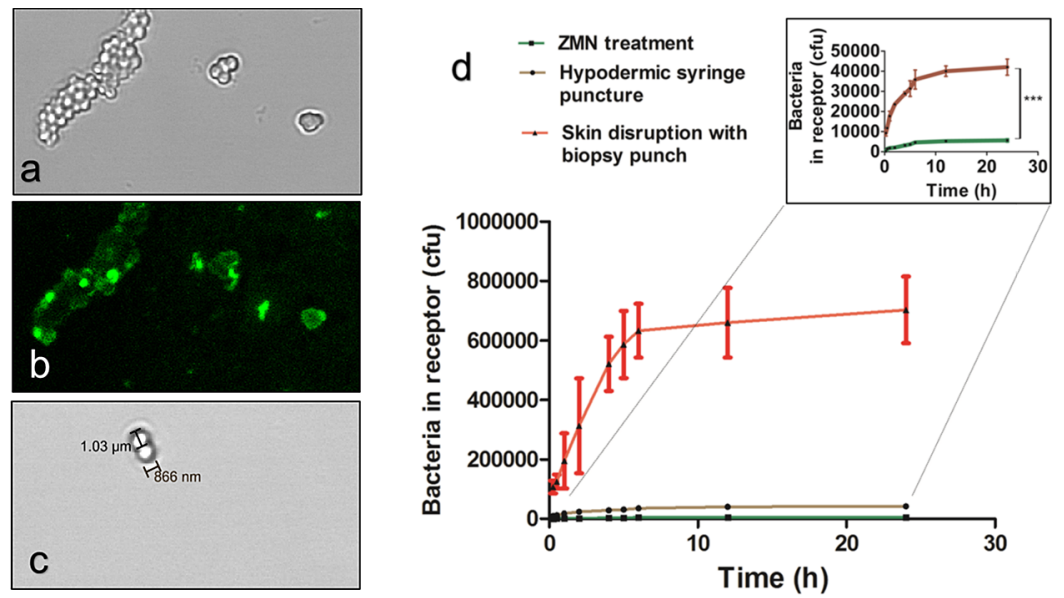

Figure 5. FITC-labeled S. epidermidis in (a) bright field and (b) dark field photographed using $10 \times$ objective lens. (c) Bacteria size measurement photographed using 20x objective lens. (d) Colony forming units of S. epidermidis in the receptor compartment of the Franz diffusion cell at various time points after treatment using ZMNs, hypodermic syringe, and biopsy punch. Data represent mean $\pm \mathrm{SD}(n=3)$. *** represents the significantly different values $(p<0.0001, t$-test $)$.

shows the OVA bands after SDS-PAGE, where the band densities decreased with the increase in the storage temperature. OVA has been shown to form aggregates in less than 2 min at temperature between 70 and $80^{\circ} \mathrm{C}$, as confirmed using gel permeation chromatography and differential scanning calorimetry. $^{26}$

CD spectroscopy was used to study the secondary structure of OVA after storage under different environmental conditions. Figure 4d,e shows the residual molar ellipticity versus wavelength graphs for OVA released from ZMNs stored under different stability conditions. The $\mathrm{CD}$ spectra of native OVA showed two strong negative minima at 208 and $222 \mathrm{~nm}$ wavelengths. These bands are indicative of the $\alpha$-helical structure of OVA. ${ }^{27}$ There was no significant change in the minima at 208 and $222 \mathrm{~nm}$ after storage of OVA-coated ZMNs under cold conditions and at room conditions for up to 60 days. The CD spectra of OVA after 90-day storage changed in comparison with the native structure. The decrease in the intensity of all $\alpha$-helix bands shows a change in the native structure after 90-day storage (Figure 4d,e). Maintenance of the structural integrity of a protein is essential for its activity. The CD spectroscopy results indicated that the secondary structure of OVA was not greatly altered upon storage under cold and room conditions for up to 60 days.

Figure $4 \mathrm{f}-\mathrm{h}$ shows the force versus displacement plots obtained from the texture analyzer for ZMNs stored under different stability conditions for up to 90 days. There was no significant $(p>0.05)$ decrease in the break force for ZMNs stored at RT or under cold conditions. However, when stored under accelerated conditions, the break force decreased significantly $(p<0.05)$ compared with that of the newly prepared ZMNs. This indicates that the needles become softer during storage under accelerated conditions, and the mechanical strength of ZMNs depends on the temperature and humidity of the storage conditions.

Good stability of antigen-entrapped polymeric microneedles has been reported over different storage periods and conditions, although long-term and stress stability data for such formulations are limited. ${ }^{28,29}$ It has been proposed that coating of vaccines on microneedles can reduce the need for cold chain maintenance in contrast to injectable vaccine formulations. ${ }^{30}$ Here, we provide a proof-of-concept, where antigen-coated
ZMNs were relatively stable under room conditions. However, further studies are required to investigate whether this phenomenon can be extended for a longer duration and be applicable for other antigens.

Skin Penetration of Bacteria after ZMN and Hypodermic Needle Pretreatment. Staphylococcus epidermidis was labeled with FITC under alkaline conditions. The bacterial suspension was serially diluted, plated onto agar, and incubated at $37{ }^{\circ} \mathrm{C}$ for $24-48 \mathrm{~h}$ for validating the $\mathrm{cfu} / \mathrm{mL}$ concentration. A smear of bacterial suspension on a glass slide was examined under a confocal microscope for bacterial morphology and fluorescence due to FITC labeling. Figure 5 shows the confocal images captured under bright field and dark field. S. epidermidis can be seen arranged in grape clusterlike structures. ${ }^{31}$ Surface conjugation of bacteria with FITC and other dyes has previously been reported. ${ }^{32}$ The bacteria are reported to be $1-2 \mu \mathrm{m}$ in size, which can also be seen in Figure 5c. $S$. epidermidis formed raised, white colored, distinct colonies when grown on nutrient agar plates. $^{31}$

Table 2 shows the extent of skin penetration of $S$. epidermidis. In the control group, $1.27 \pm 0.12 \times 10^{6} \mathrm{cfu}$ was found to be

Table 1. Storage Conditions for Stability Study of Blank and OVA-Coated ZMNs

\begin{tabular}{cccc}
$\begin{array}{c}\text { stability } \\
\text { condition }\end{array}$ & $\begin{array}{c}\text { temperature } \\
\left({ }^{\circ} \mathrm{C}\right)\end{array}$ & humidity & packaging \\
$\begin{array}{c}\text { cold } \\
\text { conditions }\end{array}$ & $2-8$ & not monitored & $\begin{array}{c}\text { ZMNs placed in 12-well } \\
\text { plates and wrapped with } \\
\text { an aluminum foil }\end{array}$ \\
RT & 25 & not monitored & $\begin{array}{l}\text { ZMNs placed in 12-well } \\
\text { plates and wrapped with } \\
\text { an aluminum foil }\end{array}$ \\
$\begin{array}{c}\text { accelerated } \\
\text { conditions }\end{array}$ & 40 & $75 \pm 5 \% \mathrm{RH}$ & $\begin{array}{l}\text { ZMNs individually wrapped } \\
\text { loosely in aluminum foil } \\
\text { and placed in a plastic } \\
\text { container }\end{array}$ \\
\hline
\end{tabular}

adhered to the skin surface out of $10^{7} \mathrm{cfu}$ bacteria placed in the donor compartment. This number was taken as the denominator for calculating the percentage of bacteria permeated across the skin or adhered to treatment devices. Approximately fourfold greater cfu of bacteria adhered to the ZMNs compared with the hypodermic needle. This can be 
Table 2. Skin Penetration of $S$. epidermidis after Treatment with ZMNs, Hypodermic Needle, or Biopsy Punch ${ }^{a}$

$\begin{array}{lcc}\begin{array}{r}\text { bacteria cfu in the receptor } \\ \text { after } 24 \text { h of treatment }(\% \\ \text { of cfu adhered to the skin } \\ \text { surface) }\end{array} & \begin{array}{r}\text { bacteria adhered to the } \\ \text { hypodermic needle, ZMN or } \\ \text { biopsy punch } \% \text { of cfu adhered } \\ \text { to the skin surface) }\end{array} \\ \begin{array}{c}\text { treatment } \\ \begin{array}{c}\text { hypodermic } \\ \text { needle }\end{array}\end{array} & \begin{array}{r}4.2 \pm 0.40 \times 10^{5}(3.29 \%) \\ 0.0186 \pm 0.0017 \times 10^{5}(0.14 \%)\end{array} \\ \begin{array}{c}\text { ZMN } \\ \text { treatment } \\ \text { for 30 min }\end{array} & \begin{array}{c}0.0563 \pm 0.0079 \times 10^{5} \\ (0.44 \%)\end{array} & 0.0641 \pm 0.0091 \times 10^{5}(0.50 \%) \\ \text { skin } \\ \text { disruption } \\ \text { with biopsy } \\ \text { punch }\end{array}$

${ }^{a}$ The values are represented as the percentage of colony-forming units found attached to the skin surface after equilibrating the skin surface with bacteria for $24 \mathrm{~h}$. Data represent mean $\pm \mathrm{SD}, n=3$.

attributed to the greater exposed surface area of $\mathrm{ZMNs}(117$ $\mathrm{mm}^{2}$ ) compared with the $24 \mathrm{G}$ hypodermic syringe $\left(70 \mathrm{~mm}^{2}\right)$. The bacteria adhered to the biopsy punch was on the order of $10^{5} \mathrm{cfu}$. After the application of $\mathrm{ZMNs}$ on the skin, the permeation of bacteria increased up to $6 \mathrm{~h}$ and then plateaued off over the next $18 \mathrm{~h}$ (Figure 5d). Of the total bacterial load, $3.29 \%$ bacteria permeated across the skin punctured with the hypodermic needle in $24 \mathrm{~h}$. Meanwhile, after ZMN treatment, it was only $0.44 \%$ of the total bacterial count. This could be related to the bigger size of the pore created by the hypodermic needle compared with the microneedles. ${ }^{32}$

A confocal microscope was used to compare the depth of skin penetration of $S$. epidermidis after the application of the hypodermic needle or ZMN. Figure 6 shows the optical sections of the skin at varying depths from the surface up to $230 \mu \mathrm{m}$ in the XYZ plane. The fluorescence associated with the bacteria can be found up to a depth of 230 and $120 \mu \mathrm{m}$ inside of the skin after treatment with the hypodermic needle and the $\mathrm{ZMN}$, respectively. Figure $6 \mathrm{~b}, \mathrm{e}$ shows the $3 \mathrm{D}$ reconstructed image.

Earlier reports claimed lower microbial penetration in the skin after the microneedle treatment; however, only a few reports presented experimental results. Donnelly and coworkers compared the penetration of radiolabeled microorganisms S. epidermidis, Pseudomonas aeruginosa, and Candida albicans through porcine skin after treatment with a hypodermic needle or a microneedle array. Following hypodermic needle treatment, 48.0 and $3.5 \%$ of load on the stratum corneum was detected in the receptor compartment for C. albicans and S. epidermidis after $24 \mathrm{~h}^{33}$

Transcutaneous Immunization Using OVA-Coated ZMNs. Three strategies can be used to deliver drugs into the skin using solid microneedles. ${ }^{34}$ In this study, we have compared three approaches to study OVA-specific immunization including OVA topical application after ZMN pretreatment, OVA-entrapped ZMNs, and OVA-coated ZMNs.

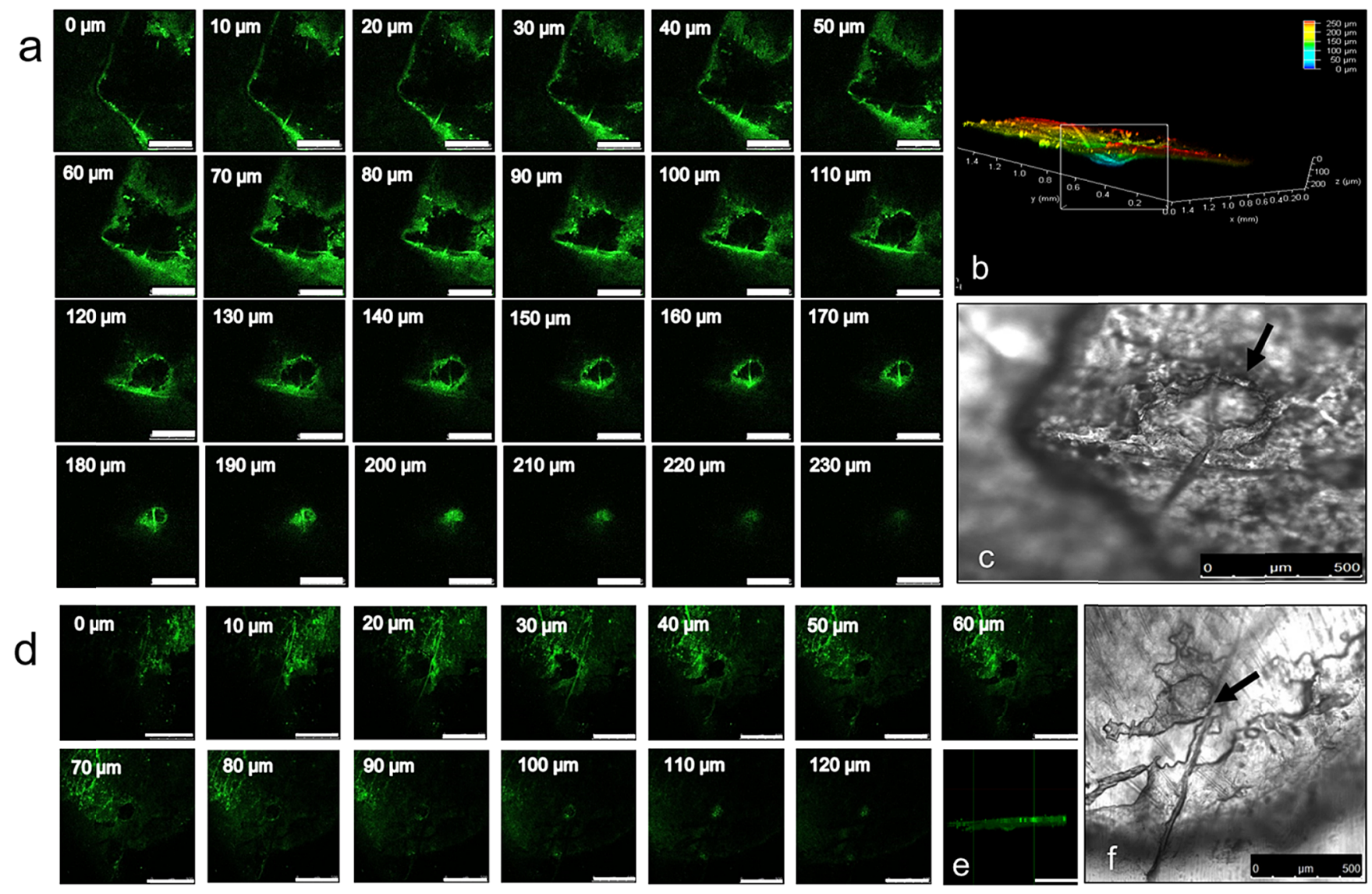

Figure 6. Confocal micrographs of FITC-labeled S. epidermidis obtained through optical sections from the surface to inside of the skin after the application of the hypodermic needle (a) and ZMN (d). The scale bar represents $500 \mu \mathrm{m}$. Three-dimensional reconstruction of the microchannel created due to bacteria permeation after puncture by the hypodermic needle (b) and ZMN treatment (e). Bright-field image of the pore created by the hypodermic needle (c) and ZMN (f). The arrow indicates pore location. 
a OVA specific IgG response

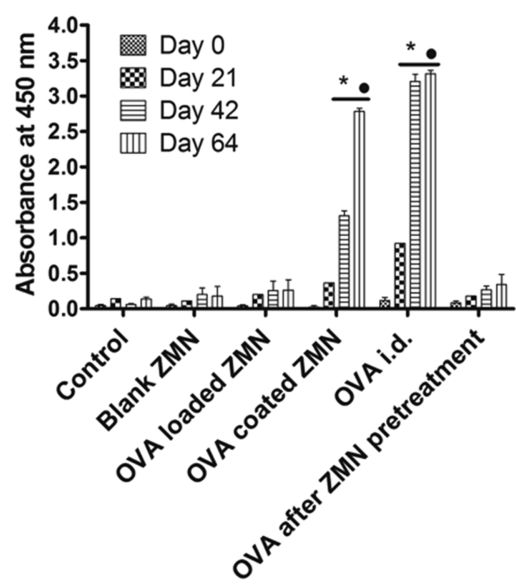

b

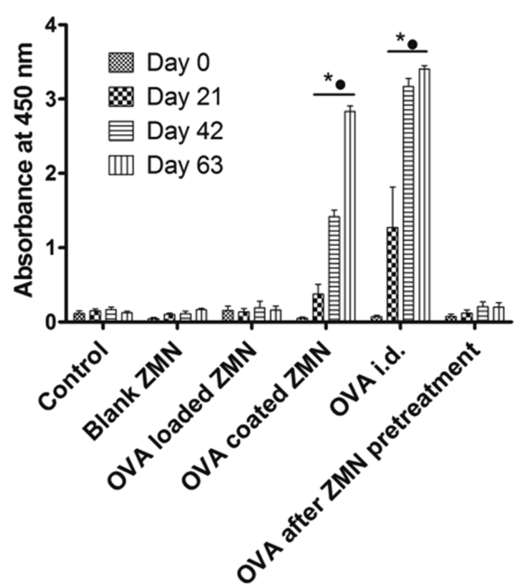

C OVA specific IgG2a response

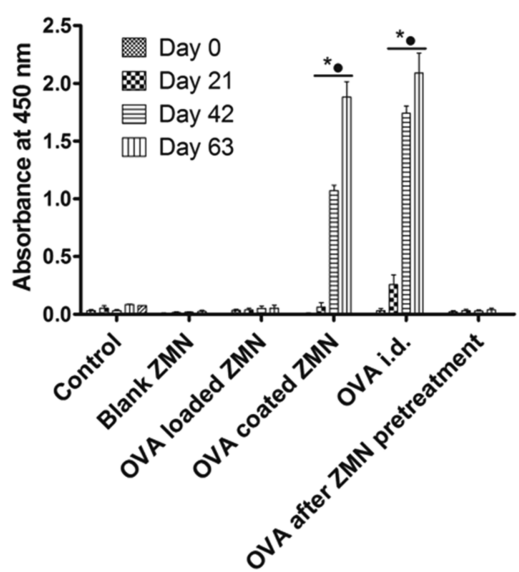

Figure 7. OVA-specific serum IgG (a), IgG1 (b), and IgG2a (c) responses delivered using ZMNs and intradermal vaccination. Results are shown as mean \pm standard error of the mean $(\mathrm{SEM})(n=4)$, and statistical significance was determined using a two-way analysis of variance (ANOVA) with a Bonferroni post-test. $\left.*^{*}\right)$ and $(\bullet)$ represent the significantly different $(p<0.001)$ values compared with those of control and blank ZMNs, respectively, for the corresponding days. It should be noted that the amount of OVA delivered was approximately 100 times greater for OVA-coated ZMNs compared with OVA intradermal administration.

Mice were immunized with a primary and two booster doses. Figure 7 shows the total IgG (a), IgG1 (b), and IgG2a (c) antiOVA antibody response on days $0,21,42$, and 63 for different groups. A time-dependent increase in the antibody titers was observed after immunization using all formulations. Blank ZMNs were also studied to investigate any nonspecific immune response. No significant antibody response was found for blank ZMNs in comparison with the control animal group. Intradermal injection of OVA induced significantly $(p<0.05)$ greater antibody response for IgG, IgG1, and IgG2a compared with that of the control group. All mice that were intradermally injected with OVA produced specific IgG antibodies after the prime immunization. In the case of OVA-coated ZMNs, induction of an antibody response was slower compared with OVA administered through intradermal injection. After day 42 and 64, the antibody response for OVA-coated ZMNs and OVA intradermal injection was significantly higher $(p<0.001)$ compared with that of control and treatment with blank. As the initial administered dose of OVA was different among different $\mathrm{ZMN}$ administration strategies and intradermal injection, the antibody response among these groups was not statistically compared (Figure 7). In the case of OVA-entrapped ZMNs or OVA topical application after ZMN pretreatment, there was no significant improvement in the antibody response compared with that of the control group. Furthermore, it was found that OVA administered through intradermal and coated ZMNs provided greater humoral immune response (IgG1 response) compared with the cellular response (IgG2a response, Figure 7).

Application of OVA-coated microneedle arrays to BALB/c mice resulted in greater antibody response. However, it should be noted that the initial loading dose was different for the three different administration strategies. Furthermore, the amount of OVA released within the skin was different for OVA-coated ZMNs and OVA-entrapped ZMNs. It should be noted that a significantly greater amount of OVA was required when OVA was delivered using coated $\mathrm{ZMNs}$ to show antibody response similar to intradermal administration. This could be attributed to the physical and chemical changes in OVA during the preparation and application of OVA-coated ZMNs. There are several reports with OVA immunization using microneedle arrays. van der Maaden et al. have reported mice immunized with OVA-coated $\mathrm{pH}$-sensitive silicon microneedle arrays. ${ }^{35}$ Effective induction of $\operatorname{IgG}$ responses was observed compared with intradermal or subcutaneous OVA injection. However, similar to the results from the present study, the induction time was longer and required successive immunizations. Widera and co-workers reported significantly greater OVA-specific IgG responses with OVA-coated $400 \mu \mathrm{m}$ long microneedles than that with OVA intramuscular injection in hairless guinea pig model. ${ }^{36}$ The size and shape of the needles were shown to influence the delivery of OVA into the skin and the subsequent immune response. Higher OVA-specific IgG response was found after application of OVA-loaded nanoparticles on mouse skin previously treated with longer microneedles $(1000 \mu \mathrm{m})$ compared with shorter microneedles $(200$ and $500 \mu \mathrm{m}){ }^{37}$ By contrast, other studies reported no effect of microneedle length on OVA delivery. ${ }^{36}$ Topical application of OVA after ZMN pretreatment did not result in greater immune response. This could be attributed to the lower penetration of OVA in the skin through the pores created by ZMNs. While more studies would be required to understand the transport of OVA through skin pores created by ZMNs, the negatively charged OVA at neutral $\mathrm{pH}$ may penetrate less through the negatively charged skin. Further studies using OVA and other model antigens would be required to provide a greater understanding on the influence of coating and the release mechanism on transcutaneous antigen presentation. These results would encourage further investigation in the utilization of ZMNs to deliver antigen for immunization against infectious agents such as influenza virus.

Splenocyte Proliferation Assay. Long-term memory response is one of the key features of an effective vaccine delivery system. The ability of memory $\mathrm{T}$-cells to recognize the antigen can be determined by studying the proliferation of splenocytes of preimmunized mice upon restimulation with antigen. The use of MTT assay for this purpose has been reported earlier. ${ }^{38}$ The proliferation of splenocytes was higher in the OVA intradermal and the OVA-coated ZMN group when restimulated with OVA. The stimulation index (SI) of OVA-coated ZMNs was significantly higher $(p<0.05)$ 
compared with that of the control group (Figure 8). The increased proliferation of splenocytes in mice treated with
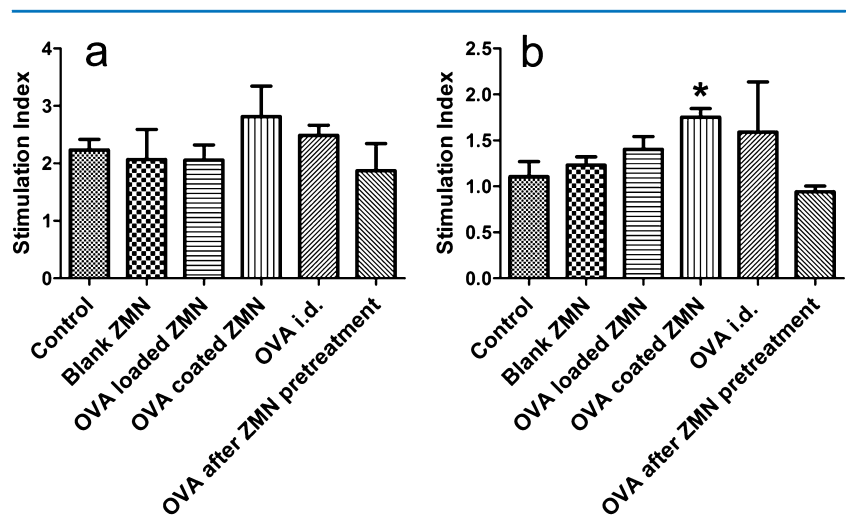

Figure 8. Splenocytes of preimmunized mice stimulated with Roswell Park Memorial Institute (RPMI) 1640 alone, OVA, and concanavalin A mitogen for $72 \mathrm{~h}$. SI was calculated by dividing the absorbance value of concanavalin A (a) or OVA (b) treatment group with that of RPMI 1640 treated group. The values are presented as mean $\pm \operatorname{SEM}(n=4)$. $(*)$ represents the significantly different $(p<0.05)$ values compared with control. An unpaired $t$ test was used in the statistical analysis of the experimental data.

OVA-coated ZMNs suggests their ability to enhance the antigen presentation to the T-cells and to induce a long-lasting immune response.

\section{CONCLUSIONS}

We have shown here that biodegradable and generally regarded as safe (GRAS) zein can be molded to achieve a microneedle array. This microneedle array showed sufficient mechanical strength to penetrate the skin. This is the first time zein protein is used for the preparation of a microneedle array. Zein can be easily casted and shows potential for scale-up using the micromolding technique. The model antigen, OVA can be entrapped or coated on to ZMNs. OVA-loaded ZMNs were stable and provided a significantly lower microbial penetration compared with the application of a conventional hypodermic needle. The approach of OVA-coated ZMNs was found efficient in skin delivery of OVA compared with that of OVA-entrapped ZMNs and topical OVA application after ZMN pretreatment. However, a larger dose of OVA-coated $\mathrm{ZMNs}$ is required to elicit a similar antibody response compared with that of intradermal administration. Taken together, $\mathrm{ZMN}$ can be developed for potential delivery of antigen for transcutaneous immunization.

\section{EXPERIMENTAL SECTION}

Materials. Zein and FITC were purchased from SigmaAldrich Chemical Company (Bengaluru, India). OVA from chicken egg white (catalog number A5503, with $\geq 98 \%$ assay) was purchased from Sigma-Aldrich Chemical Company and was used without any further purification. Sylgard 184 was purchased from Dow Corning (Midland, MI, USA). Stock cultures of $S$. epidermidis were obtained from Microbial Type Culture Collection and Gene Bank (MTCC), Chandigarh, India. Nutrient agar, nutrient media, RPMI 1640 culture medium, fetal bovine serum (FBS), and penicillin were purchased from Himedia Labs, India. HRP-conjugated antimouse IgG, IgG1, and IgG2a were purchased from Santa Cruz
Biotechnology Inc., USA. Milli-Q (Millipore, USA) water was used for all experiments.

Fabrication of ZMNs. Pro/ENGINEER (PTC Creo 2.0) was used to design the microneedle arrays and generate stereolithography (STL) files for 3D printing. The microneedles in the primary mold were designed with a length of $1500 \mu \mathrm{m}$, base diameter of $400 \mu \mathrm{m}$, and a tip radius of $25 \mu \mathrm{m}$. The array was designed to contain 36 microprojections in 1 $\mathrm{cm}^{2}$ area in a $6 \times 6$ pattern. This design was used to print acrylonitrile butadiene styrene (ABS) master mold using a polyjet 3D printer (Objet30 Scholar, Stratasys Inc., USA). This master mold was subsequently used for the fabrication of a production mold made of PDMS. Sylgard 184 silicone elastomer and a curing agent were mixed in a 10:1 w/w ratio and allowed to stand for $30 \mathrm{~min}$ for the removal of air bubbles. This mixture was poured over the ABS mold until it was completely filled. Entrapped air bubbles were removed by vacuum application for $10 \mathrm{~min}$. The PDMS mixture was then allowed to bake at $100{ }^{\circ} \mathrm{C}$ for $4 \mathrm{~h}$ in a hot air oven. Completely cured samples were then kept in a freezer to shrink and remove the PDMS mold.

Zein $(60 \mathrm{w} / \mathrm{w} \%)$ was prepared using $90 \%$ ethanol. Glycerol $(10 \mathrm{w} / \mathrm{w} \%)$ and PEG $400(10 \mathrm{w} / \mathrm{w} \%)$ were used as plasticizers. This mixture was added to the PDMS molds under vacuum and allowed to air-dry for $48 \mathrm{~h}$. Then, the ZMNs were carefully removed and used for characterization.

Characterization of ZMNs. The prepared ZMNs were examined for uniformity, length of the needle, and base diameter using an optical microscope (Olympus IX53, Olympus, Japan). The mechanical strength of the ZMNs and the required skin insertion force were studied using a texture analyzer (Stable Microsystems, UK). For determining the mechanical strength, a microneedle array was placed on a heavy duty platform with needles facing upwards. A $10 \mathrm{~mm}$ cylindrical Delrin probe (part code $\mathrm{P} / 10$ ) connected to a $50 \mathrm{~kg}$ load cell was set at the same distance from the platform for all test measurements. The texture analyzer was set in the compression mode with the probe compressing the microneedle array at a speed of $0.5 \mathrm{~mm} / \mathrm{s}$ to a maximum distance of $0.8 \mathrm{~mm}$. The probe was held in place for $5 \mathrm{~s}$. ZMNs prepared without adding plasticizers were also characterized using the same experimental parameters. Force versus displacement curve was plotted to calculate the bending force. The excised mouse skin was used to determine the required skin insertion force for the penetration of microneedles. A double-sided adhesive tape was used to adhere the $\mathrm{ZMNs}$ to a moveable $10 \mathrm{~mm}$ cylindrical probe. The skin sample was secured on a polystyrene block with the epidermis facing the probe. The probe was lowered onto the skin at a speed of $0.5 \mathrm{~mm} / \mathrm{s}$ and a force of 0.4 or $1 \mathrm{~N} /$ needle was applied. Later, the skin sample was stained with methylene blue for $20 \mathrm{~min}$ for the visualization of pores. Photographs of the ZMNs were collected before and after insertion using a digital camera (Canon EOS 1200D with Canon EF $100 \mathrm{~mm} \mathrm{f} / 2.8$ Macro USM lens).

Preparation of OVA-Entrapped or OVA-Coated ZMNs. Two strategies were followed to load OVA in the microneedles. For the preparation of OVA-entrapped ZMNs, OVA was added to the zein mixture in the water phase, and then, this mixture was used for ZMN casting. The amount of OVA entrapped in a single needle was calculated using eq 1 . 
Amount of OVA in a single needle

$$
=\frac{\text { amount OVA added to one } \mathrm{ZMN}}{\text { average weight of OVA loaded } \mathrm{ZMN}}
$$

$X$ average weight of a single needle

OVA-coated ZMNs were prepared by the dip-coating method. The ZMNs were dipped in OVA $(40 \mathrm{mg} / \mathrm{mL}$, HEPES buffer, $\mathrm{pH} 7.0$ ) for $30 \mathrm{~min}$. The coated $\mathrm{ZMNs}$ were allowed to air-dry for $24 \mathrm{~h}$.

In Vitro Release of OVA from ZMNs. In vitro release studies were performed by placing the microneedle array in a phosphate buffer $(\mathrm{pH} 7.4)$ in a 12-well plate such that only needles were in contact with the buffer medium. The system was incubated in a shaker at $37^{\circ} \mathrm{C}$ and $40 \mathrm{rpm}$. Samples were withdrawn from the media after $1 \mathrm{~h}$. The OVA concentration in the release samples was determined using Bradford's assay. For that, $250 \mu \mathrm{L}$ of Bradford's reagent was added to $5 \mu \mathrm{L}$ of the sample in a 96-well plate and incubated for $10 \mathrm{~min}$. The absorbance was recorded at $595 \mathrm{~nm}$ wavelength. The concentration was determined after comparison with a standard calibration curve $\left(0.1-1.4 \mathrm{mg} / \mathrm{mL}\right.$ of OVA, $\left.R^{2}=0.999\right)$.

The amount of OVA released in the phosphate buffer after the insertion of ZMNs into the excised skin was evaluated. The OVA-coated ZMNs were inserted into the mouse skin for 30 min. Then, the amount of OVA released from the ZMNs in $1 \mathrm{~h}$ was determined using Bradford's assay.

Stability of OVA-Coated ZMNs. The stability of OVA released from the OVA-coated ZMNs was determined using SDS-PAGE (5\% stacking gel and 12\% resolving gel, $0.75 \mathrm{~mm}$ thickness). OVA released from the OVA-coated ZMNs before and after the insertion into the excised mouse skin was collected and mixed with $5 \times$ sample loading buffer $[\beta$ mercaptoethanol (5\%), bromophenol blue (0.02\%), glycerol (30\%), SDS (10\%), and Tris-Cl (250 mM, pH 6.8)]. Electrophoresis was performed in a vertical gel electrophoresis unit (Hoefer Inc., USA) at $100 \mathrm{~V}$ for $2 \mathrm{~h}$. Protein bands were visualized (Gel Doc XR ${ }^{+}$Imaging System, Bio-Rad, USA) after staining with Coomassie brilliant blue.

The physical stability of OVA-coated ZMNs and OVA was studied after storage under different environmental conditions. Blank and OVA-coated ZMNs were stored under cold conditions $\left(2-8{ }^{\circ} \mathrm{C}\right)$, at $\mathrm{RT}$, and under accelerated storage conditions $\left(40 \pm 2{ }^{\circ} \mathrm{C}\right.$ and $\left.75 \pm 5 \% \mathrm{RH}\right)$ (Table 1). Different OVA-coated ZMN samples were collected after 15, 30, 60, and 90 days for analysis.

The amount of OVA released from the coated ZMNs in $1 \mathrm{~h}$ in the phosphate buffer ( $\mathrm{pH}$ 7.2) was determined using Bradford's assay. The integrity of the released OVA was studied using SDS-PAGE as described above. The secondary structure of OVA released from the ZMNs was evaluated using CD spectroscopy (Jasco J-1500 CD spectrometer). For that, the samples were dialyzed against a degassed buffer $(10 \mathrm{mM}$ $\mathrm{KH}_{2} \mathrm{PO}_{4}$ and $50 \mathrm{mM} \mathrm{Na} 2 \mathrm{SO}_{4}, \mathrm{pH} 7.4$ ) overnight and filtered using a $0.22 \mu \mathrm{m}$ membrane filter before the analysis. Far-UV spectra were recorded between 250 and $200 \mathrm{~nm}$ wavelengths using a cuvette of $0.1 \mathrm{~cm}$ path length at $25{ }^{\circ} \mathrm{C}$. Process parameters including scan speed $(50 \mathrm{~nm} / \mathrm{min})$, data pitch $(1$ $\mathrm{nm})$, data integration time (1 s), and number of accumulations (3) were kept constant. Data were represented as mean residue ellipticity (deg $\mathrm{cm}^{2} / \mathrm{dmol}$ ) after buffer subtraction.

Confocal Laser Scanning Microscopy (CLSM). For CLSM studies, OVA was labeled with FITC. FITC [3 mg/
$\mathrm{mL}$ FITC in anhydrous dimethyl sulfoxide (DMSO)] was added dropwise to $4 \mathrm{~mL}$ of OVA solution $(25 \mathrm{mg} / \mathrm{mL}$ in carbonate buffer, $\mathrm{pH} 9$ ) under continuous stirring. The reaction was incubated overnight at $4{ }^{\circ} \mathrm{C}$. Free FITC was removed from the conjugate by dialyzing against PBS ( $\mathrm{pH}$ 7.4) using a regenerated cellulose membrane (mol wt cutoff $12 \mathrm{kDa}$, Spectrum Labs, USA). Thin layer chromatography with a mobile phase containing chloroform/methanol/ammonium hydroxide $(5: 4: 1)$ was performed to confirm the complete removal of free FITC. The number of moles of FITC conjugated to OVA was determined using UV-vis spectroscopy (SpectraMax M4, Molecular Devices Inc., USA). The conjugate was also characterized using FTIR (FT/IR-4200, Jasco Inc., USA). Samples ( $2 \mathrm{mg}$ ) were mixed with potassium bromide in a 1:100 ratio before the analysis. Spectra were recorded in the range of $4000-400 \mathrm{~cm}^{-1}$ wavenumber at a spectral resolution of $2 \mathrm{~cm}^{-1}$ in a dynamic reflectance sample holder.

FITC-OVA was coated on ZMNs as described above. Then, FITC-OVA-coated ZMNs were inserted into the excised BALB/c mouse skin. Fluorescence microscope (Olympus IX53, Olympus Corporation, Japan) was used to capture the fluorescence micrograph of ZMNs before and after the insertion into the skin.

To evaluate the depth of penetration of $\mathrm{ZMNs}$ and the release of OVA within the skin, CLSM studies were performed. Previously shaved excised mouse skin was used for the insertion of FITC-OVA-coated ZMNs. The ZMNs were inserted into the skin and held in place for $30 \mathrm{~min}$ using an occlusive tape. After the removal of $\mathrm{ZMNs}$, the skin sample was placed on a glass slide and held with a cellophane tape. Argon laser (488 $\mathrm{nm}$ wavelength) was used to excite FITC, and the emission intensity was detected at $520 \mathrm{~nm}$ wavelength. Images were captured in the $X Y Z$ plane (plane parallel to the mouse skin) using a $10 \times$ objective lens. The skin surface $(z=0 \mu \mathrm{m})$ was defined as the imaging plane with the brightest fluorescence. Optical sections were obtained at a $1 \mu \mathrm{m}$ step size from the skin surface through the $z$-axis. Other parameters including scan size $(512 \times 512)$, scan speed $(400 \mathrm{~Hz})$, pinhole $(53 \mu \mathrm{m})$, pinhole airy (1 AU) laser $(0.7998 \%$ of $0.0390 \mathrm{~W})$, and gain (100) were kept constant. The 3D confocal reconstruction images were also obtained to visualize the penetration of microneedles in the skin.

Histological Examination. The excised BALB/c mouse abdominal skin was mounted on a polystyrene block, and OVAcoated ZMNs were inserted in the skin for $30 \mathrm{~min}$. Then, the skin sample was embedded in an optimum cutting temperature (OCT) compound at $-80{ }^{\circ} \mathrm{C}$. The skin sample was sectioned at a thickness of $6 \mu \mathrm{m}$ using a cryostat (CM1520, Leica Biosystems, Germany). Later, the skin sections were dried overnight and stained with hematoxylin and eosin (SigmaAldrich). Microscopic images were acquired using an optical microscope.

Skin Penetration of Bacteria after ZMN Application. To study the influence of ZMN application on skin penetration of microorganisms, FITC-labeled $S$. epidermidis was used. Freeze-dried S. epidermidis (MTCC 435) cultures were reconstituted using a nutrient medium and subcultured twice. Bacterial cells were harvested by centrifugation at $10000 \mathrm{~g}$ at 4 ${ }^{\circ} \mathrm{C}$ for $5 \mathrm{~min}$. The bacterial cells were then resuspended in 1 $\mathrm{mL}$ of $0.1 \mathrm{M}$ sodium bicarbonate buffer. The optical density was measured at $600 \mathrm{~nm}$ and adjusted at 0.1 to obtain $10^{7} \mathrm{cfu} /$ $\mathrm{mL}$. This was further validated by total viable counting upon 
plating onto agar plates and counting after incubating at $37{ }^{\circ} \mathrm{C}$ for $24-48 \mathrm{~h}$. FITC stock solution $(250 \mu \mathrm{L}$ of $10 \mathrm{mg} / \mathrm{mL}$ in DMSO) was added for every $5 \mathrm{~mL}$ of bacterial suspension. The culture was incubated while shaking for $30 \mathrm{~min}$ in the dark. Then, the bacterial cells were washed three times with sterile phosphate buffer to remove unbound FITC. The cells were resuspended in the nutrient medium, and the optical density was determined. A sample of $1 \mu \mathrm{L}$ volume was smeared onto a glass slide, fixed with heat, and observed under bright field and a fluorescence microscope. The bacterial suspension was stored at $2-8{ }^{\circ} \mathrm{C}$ for not more than 1 week for further experimentation.

The permeation of $S$. epidermidis across the mouse skin was studied using a Franz diffusion cell apparatus (Permegear Inc., USA). The skin sample was sandwiched between the donor and receptor compartments ( $5 \mathrm{~mL}$ of degassed and sterilized PBS). The complete setup was maintained at $37^{\circ} \mathrm{C}$ by recirculating water from a temperature-controlled water bath. The donor compartment was charged with $1 \mathrm{~mL}$ aliquot of FITC-labeled $S$. epidermidis $\left(10^{7} \mathrm{cfu}\right)$ and incubated for $24 \mathrm{~h}$ under sterile conditions. The donor compartment was covered with Parafilm. After $24 \mathrm{~h}$, the culture from the donor compartment was withdrawn, and the skin sample was treated in three different methods: puncturing with a hypodermic needle, inserting the ZMNs, and disrupting the skin using a biopsy punch. A 24G hypodermic needle was inserted completely into the skin and removed within $30 \mathrm{~s}$. The ZMNs were inserted in the skin sample for $30 \mathrm{~min}$. ZMNs were previously exposed to UV light for $15 \mathrm{~min}$ for reducing bioburden. A sterile biopsy punch of diameter $8 \mathrm{~mm}$ was used to disrupt the skin surface by punching. The used hypodermic syringe, ZMNs, and biopsy punch were placed in $5 \mathrm{~mL}$ of sterile PBS and ultrasonicated for 15 min to dislodge all bacteria. This PBS sample was plated on agar and incubated at $37{ }^{\circ} \mathrm{C}$ for $24 \mathrm{~h}$ to count the colonyforming units. Similarly, for control measurements, the bacteria attached to the skin surface were dislodged and plated onto agar for total viable colony counting.

Furthermore, samples $(100 \mu \mathrm{L})$ were withdrawn from the receptor compartment after $0.25,0.5,1,2,4,5,6,12$, and $24 \mathrm{~h}$ of skin treatment. Total viable count of bacteria was determined after $24 \mathrm{~h}$ of incubation at $37^{\circ} \mathrm{C}$ in nutrient agar. For CLSM studies, the skin sample was placed on a glass slide and held with cellophane tape. Images were acquired using CLSM as described above.

Transcutaneous Immunization Studies. Female BALB/ c mice (4-6 weeks) were procured from National Institute of Nutrition, Hyderabad, India. All experiments were performed after approval from the institutional animal ethics committee (IAEC) of BITS, Pilani. The mice were fed with a standard laboratory diet and were provided with clean drinking water ad libitum. The animals were divided into six groups of five mice in each group. The groups include (1) control (no ZMN insertion); (2) blank ZMN; (3) OVA-entrapped ZMN; (4) OVA-coated ZMN; (5) blank ZMN insertion followed by OVA solution application; and (6) OVA intradermal injection. OVA intradermal injections were given by dissolving OVA in PBS ( $\mathrm{pH}$ 7.4). For topical immunization, the mice were anesthetized with isoflurane (E-Z systems, USA), and the dorsal skin was shaved using a hair clipper. The skin was wiped with $70 \%$ ethanol. The $\mathrm{ZMN}$ was inserted into the skin and held in place using an occlusive tape. The $\mathrm{ZMN}$ was inserted for $30 \mathrm{~min}$ or 4 $\mathrm{h}$ for OVA-coated $\mathrm{ZMN}$ and OVA-entrapped ZMN, respectively. For OVA application after ZMN pretreatment, the OVA solution was topically applied after $1 \mathrm{~min}$ insertion of the blank ZMN. The amount of OVA administered through intradermal injection was $5 \mu \mathrm{g}$. The amount of OVA topically applied after ZMN pretreatment was $100 \mu \mathrm{g}$. On the other hand, the amount of OVA delivered using a ZMN that was released within the skin after the insertion is not quantified. However, OVA release studies ( $1 \mathrm{~h}$ sampling) were performed to determine approximately the amount of OVA released inside of the skin. The amount of OVA available within the skin after OVA-entrapped ZMN insertion was $\sim 80 \mu \mathrm{g}$. In the case of OVA-coated ZMNs, the total OVA released was $\sim 600 \mu \mathrm{g}$. For all treatment groups, the mice were immunized on days 1,22 , and 43. Blood samples were collected from the retro-orbital plexus on days 21,42 , and 63 . The serum was separated from the blood by centrifugation at $4000 \mathrm{rpm}$ for $20 \mathrm{~min}$ at $4{ }^{\circ} \mathrm{C}$ and stored at $-80{ }^{\circ} \mathrm{C}$ for further analysis.

The enzyme- linked immunosorbent assay (ELISA) technique was used to determine the OVA-specific antibodies (IgG, IgG1, and IgG2a) in the serum samples. High binding flat bottom microtiter plates (96-well, Himedia Labs, India) were coated with OVA ( $1 \mu \mathrm{g} /$ well in bicarbonate buffer, $\mathrm{pH} 9.6)$. The plates were incubated at $4{ }^{\circ} \mathrm{C}$ overnight. Then, the unbound antigen was removed by washing three times with a wash buffer (PBS $7.4+0.05 \%$ Tween 20). Free sites were blocked with $200 \mu \mathrm{L}$ of blocking buffer [PBS $7.4+1 \%$ bovine serum albumin (BSA) + 0.05\% TWEEN 20] for $30 \mathrm{~min}$ followed by a three-time wash step. Serum samples $(100 \mu \mathrm{L}$, diluted 1:200 for total IgG, 1:160 for IgG1, and 1:40 for IgG2a in the sample diluent, PBS $7.4+1 \%$ BSA) were added to the wells and incubated for $1 \mathrm{~h}$. Later, HRP-conjugated anti-mouse $\mathrm{IgG} / \mathrm{IgG} 1 / \operatorname{IgG} 2 \mathrm{a}(100 \mu \mathrm{L} ; 1: 6000$ in the sample diluent) was incubated for $1 \mathrm{~h}$ followed by a five-time wash step. Finally, 100 $\mu \mathrm{L}$ of 3,3',5,5'-tetramethylbenzidine (TMB) substrate solution was added to each well and incubated in the dark for $15 \mathrm{~min}$. The reaction was stopped by adding $100 \mu \mathrm{L}$ of $2 \mathrm{~N} \mathrm{H}_{2} \mathrm{SO}_{4}$. The absorbance intensity was determined at $450 \mathrm{~nm}$ wavelength using a microplate reader (SpectraMax M4, Molecular Devices Inc., USA), and antibody titers were determined against a standard calibration curve.

Splenocyte Proliferation Assay. In vitro splenocyte proliferation assay was performed to investigate the ability of memory T-cells to recognize the antigen upon restimulation. The mice were killed on day 64 after immunization, and the spleen was harvested under sterile conditions. The spleen was placed in ice-cold PBS ( $\mathrm{pH}$ 7.4) and gently mashed using the back of a syringe plunger. The loose spleen mass was then passed through a cell strainer ( $40 \mu \mathrm{m}$ pore size, Himedia Labs, India) into $15 \mathrm{~mL}$ centrifuge tubes. The tubes were centrifuged at $2500 \mathrm{rpm}$ for $5 \mathrm{~min}$. The cells were washed twice with icecold PBS, and a single cell suspension of splenocytes was prepared in RPMI 1640 medium supplemented with $1 \%$ FBS. The suspension was centrifuged at $2500 \mathrm{rpm}$ at $25{ }^{\circ} \mathrm{C}$ for 5 min, and the supernatant was discarded. RBC lysis buffer (150 $\mathrm{mM} \mathrm{NH}_{4} \mathrm{Cl}, 10 \mathrm{mM} \mathrm{KHCO}_{3}$, and $1 \mathrm{mM}$ EDTA-2Na, $\mathrm{pH}$ 7.2) was added to lyse the erythrocytes. The cells were again centrifuged after the addition of RPMI 1640 medium. The pellet was redispersed in RPMI 1640 media, and the cells were counted using a Neubauer chamber. Splenocytes were seeded in a 96-well plate at 50000 cells/well and treated with the blank RPMI medium, OVA $(50 \mu \mathrm{g} / \mathrm{mL})$, or positive control concanavalin A mitogen (Con A) $(1 \mu \mathrm{g} / \mathrm{mL})$ for $72 \mathrm{~h}$. At the end of treatment, the medium was removed, and the cells were incubated with $50 \mu \mathrm{L}$ of 3-(4,5-dimethylthiazol-2-yl)-2,5- 
diphenyltetrazolium bromide (MTT) solution $(0.5 \mathrm{mg} / \mathrm{mL})$ for $4 \mathrm{~h}$. Then, DMSO $(150 \mu \mathrm{L})$ was added to dissolve the formazan crystals. The absorbance was measured at $540 \mathrm{~nm}$ using a UV-vis spectrophotometer. SI was calculated using eq 2.

$$
\begin{aligned}
& \text { Stimulation index }(\mathrm{SI}) \\
& \qquad=\frac{A_{540 \mathrm{~nm}} \text { of Con A or OVA treated cells }}{A_{540 \mathrm{~nm}} \text { of RPMI } 1640 \text { treated cells }}
\end{aligned}
$$

\section{ASSOCIATED CONTENT}

\section{S Supporting Information}

The Supporting Information is available free of charge on the ACS Publications website at DOI: 10.1021/acsomega.7b00343.

Confirmation of FITC conjugation with OVA using thin layer chromatography; shift in $\lambda_{\max }$ after FITC conjugation of OVA; FTIR spectra of FITC, OVA, and FITC OVA conjugate; and force versus displacement plot for ZMNs prepared with and without plasticizers (PDF)

\section{AUTHOR INFORMATION}

\section{Corresponding Author}

*E-mail: vamsi@hyderabad.bits-pilani.ac.in. Fax: +91-04066303998. Phone: +91-040-66303581 (V.V.K.V.).

\section{ORCID $\odot$}

Venkata Vamsi Krishna Venuganti: 0000-0001-9686-9525

\section{Present Address}

${ }^{\dagger}$ Currently working as Development Scientist, Beckman Coulter, Beckman Coulter Bangalore Development Center, \#50B, Peenya industrial area, Bangalore 560059, Karnataka, India (S.R.C.).

\section{Author Contributions}

S.B., O.P.K., and V.V.K.V. were involved in the design of the experiments. S.B. and S.R.C. performed the experiments. S.B., O.P.K., and V.V.K.V. were involved in the analysis of data. S.B. and V.V.K.V. were involved in writing the manuscript.

\section{Funding}

This work was financially supported by BITS Pilani, Hyderabad Campus. Texture analyzer and multiplate reader were procured using a grant from the Department of Science and Technology-Fund for Improvement of Science and Technology Infrastructure (DST FIST).

\section{Notes}

The authors declare no competing financial interest.

\section{ACKNOWLEDGMENTS}

We thank Technology Business Incubator, BITS Pilani, Hyderabad Campus for providing the $3 \mathrm{D}$ printer. We also thank Swagatika Mohanty, Department of Mechanical Engineering, BITS Pilani Hyderabad Campus for help with Pro/ ENGINEER designs.

\section{REFERENCES}

(1) Babiuk, S.; Baca-Estrada, M.; Babiuk, L. A.; Ewen, C.; Foldvari, M. Cutaneous Vaccination: The Skin as an Immunologically Active Tissue and the Challenge of Antigen Delivery. J. Controlled Release 2000, 66, 199-214.
(2) Nir, Y.; Paz, A.; Sabo, E.; Potasman, I. Fear of Injections in Young Adults: Prevalence and Associations. Am. J. Trop. Med. Hyg. 2003, 68, 341-344.

(3) Simonsen, L.; Kane, A.; Lloyd, J.; Zaffran, M.; Kane, M. Unsafe Injections in the Developing World and Transmission of Bloodborne Pathogens: A Review. Bull.W. H. O. 1999, 77, 789-800.

(4) Luttge, R. Drug Delivery through Microneedles. In Microsystems for Pharmatechnology, 1st ed.; Dietzel, A., Ed.; Springer International Publishing: Switzerland, 2016; pp 275-298.

(5) Kim, Y.-C.; Park, J.-H.; Prausnitz, M. R. Microneedles for Drug and Vaccine Delivery. Adv. Drug Delivery Rev. 2012, 64, 1547-1568.

(6) Mccrudden, M. T. C.; Mcalister, E.; Courtenay, A. J.; GonzálezVázquez, P.; Singh, T. R. R.; Donnelly, R. F. Microneedle Applications in Improving Skin Appearance. Exp. Dermatol. 2015, 24, 561-566.

(7) Marshall, S.; Sahm, L. J.; Moore, A. C. The Success of Microneedle-Mediated Vaccine Delivery into Skin. Hum. Vaccines Immunother. 2016, 12, 2975-2983.

(8) Pettis, R. J.; Harvey, A. J. Microneedle Delivery: Clinical Studies and Emerging Medical Applications. Ther. Delivery 2012, 3, 357-371.

(9) Kim, Y.-C.; Prausnitz, M. R. Enabling Skin Vaccination Using New Delivery Technologies. Drug Delivery Transl. Res. 2011, 1, 7-12.

(10) Bediz, B.; Korkmaz, E.; Khilwani, R.; Donahue, C.; Erdos, G.; Falo, L. D.; Ozdoganlar, O. B. Dissolvable Microneedle Arrays for Intradermal Delivery of Biologics: Fabrication and Application. Pharm. Res. 2014, 31, 117-135.

(11) Demir, Y. K.; Akan, Z.; Kerimoglu, O. Sodium Alginate Microneedle Arrays Mediate the Transdermal Delivery of Bovine Serum Albumin. PLoS One 2013, 8, No. e63819.

(12) Park, J.-H.; Allen, M. G.; Prausnitz, M. R. Biodegradable Polymer Microneedles: Fabrication, Mechanics and Transdermal Drug Delivery. J. Controlled Release 2005, 104, 51-66.

(13) Banga, A. K. Transcutaneous Immunization via Physical Methods. In Transdermal and Intradermal Delivery of Therapeutic Agents: Application of Physical Technologies, 1st ed.; Banga, A. K., Ed.; CRC Press: Boca Raton, FL, 2011; pp 219-241.

(14) Sullivan, S. P.; Koutsonanos, D. G.; Del Pilar Martin, M.; Lee, J. W.; Zarnitsyn, V.; Choi, S. O.; Murthy, N.; Compans, R. W.; Skountzou, I.; Prausnitz, M. R. Dissolving Polymer Microneedle Patches for Influenza Vaccination. Nat. Med. 2010, 16, 915-920.

(15) Gorham, J. Analysis of Indian Corn. Quart. J. Sci. Lit. Art. 1821, $2,206-208$.

(16) Osborne, T. B. The Vegetable Proteins; Longmans, Green and Co.: New York, 1924.

(17) Coleman, C. E.; Larkins, B. A. The Prolamins of Maize. In Seed Proteins; Shewry, P. R., Casey, R., Eds.; Kluwer Academic Publishers: The Netherlands, 1999; pp 109-139.

(18) Lawton, J. W. Zein: A History of Processing and Use. Cereal Chem. 2002, 79, 1-18.

(19) Shukla, R.; Cheryan, M. Zein: The Industrial Protein from Corn. Ind. Crops Prod. 2001, 13, 171-192.

(20) Lu, Y.; Mantha, S. N.; Crowder, D. C.; Chinchilla, S.; Shah, K. N.; Yun, Y. H.; Wicker, R. B.; Choi, J.-W. Microstereolithography and Characterization of Poly(propylene fumarate)-Based Drug-Loaded Microneedle Arrays. Biofabrication 2015, 7, 045001.

(21) Lee, I.-C.; He, J.-S.; Tsai, M.-T.; Lin, K.-C. Fabrication of a Novel Partially Dissolving Polymer Microneedle Patch for Transdermal Drug Delivery. J. Mater. Chem. B 2015, 3, 276-285.

(22) Wang, P.-C.; Wester, B. A.; Rajaraman, S.; Paik, S.-J.; Kim, S.-H.; Allen, M. G. Hollow polymer microneedle array fabricated by photolithography process combined with micromolding technique. In Annual International Conference of the IEEE; Engineering in Medicine and Biology Society, Sept 3-6, 2009; pp 7026-7029.

(23) Yuan, W.; Yang, S.; Feng, Y.; Zhang, L.; Chen, N.; Jin, T. A Scalable Fabrication Process of Polymer Microneedles. Int. J. Nanomed. 2012, 7, 1415-1422.

(24) Gill, H. S.; Prausnitz, M. R. Coated Microneedles for Transdermal Delivery. J. Controlled Release 2007, 117, 227-237.

(25) Kim, Y.-C.; Quan, F.-S.; Compans, R. W.; Kang, S.-M.; Prausnitz, M. R. Formulation and Coating of Microneedles with 
Inactivated Influenza Virus to Improve Vaccine Stability and Immunogenicity. J. Controlled Release 2010, 142, 187-195.

(26) Weijers, M.; Barneveld, P. A.; Stuart, M. A. C.; Visschers, R. W. Heat-Induced Denaturation and Aggregation of Ovalbumin at Neutral pH Described by Irreversible First-Order Kinetics. Protein Sci. 2003, 12, 2693-2703.

(27) Batra, P. P.; Sasa, K.; Ueki, T.; Takeda, K. Circular Dichroic Study of Conformational Changes in Ovalbumin Induced by Modification of Sulfhydryl Groups and Disulfide Reduction. J. Protein Chem. 1989, 8, 609-617.

(28) Lee, J. W.; Choi, S.-O.; Felner, E. I.; Prausnitz, M. R. Dissolving Microneedle Patch for Transdermal Delivery of Human Growth Hormone. Small 2011, 7, 531-539.

(29) Lee, J. W.; Park, J.-H.; Prausnitz, M. R. Dissolving Microneedles for Transdermal Drug Delivery. Biomaterials 2008, 29, 2113-2124.

(30) DeMuth, P. C.; Garcia-Beltran, W. F.; Ai-Ling, M. L.; Hammond, P. T.; Irvine, D. J. Composite Dissolving Microneedles for Coordinated Control of Antigen and Adjuvant Delivery Kinetics in Transcutaneous Vaccination. Adv. Funct. Mater. 2013, 23, 161-172.

(31) Wilson, B. A.; Salyers, A. A.; Whitt, D. D.; Winkler, M. E. The Gram-Positive Opportunistic Pathogens. In Bacterial Pathogenesis: A Molecular Approach, 3rd ed.; Wilson, B. A., Salyers, A. A., Whitt, D. D., Winkler, M. E., Eds.; ASM Press: Washington, DC, 2002; pp 399-436.

(32) Pikaar, J. C.; Voorhout, W. F.; van Golde, L. M. G.; Verhoef, J.; Van Strijp, J. A. G.; van Iwaarden, J. F. Opsonic Activities of Surfactant Proteins A and D in Phagocytosis of Gram-Negative Bacteria by Alveolar Macrophages. J. Infect. Dis. 1995, 172, 481-489.

(33) Donnelly, R. F.; Singh, T. R. R.; Tunney, M. M.; Morrow, D. I. J.; McCarron, P. A.; O’Mahony, C.; Woolfson, A. D. Microneedle Arrays Allow Lower Microbial Penetration Than Hypodermic Needles In Vitro. Pharm. Res. 2009, 26, 2513-2522.

(34) Van Der Maaden, K.; Jiskoot, W.; Bouwstra, J. Microneedle Technologies for (Trans)Dermal Drug and Vaccine Delivery. J. Controlled Release 2012, 161, 645-655.

(35) Van Der Maaden, K.; Varypataki, E. M.; Romeijn, S.; Ossendorp, F.; Jiskoot, W.; Bouwstra, J. Ovalbumin-Coated pHSensitive Microneedle Arrays Effectively Induce Ovalbumin-Specific Antibody and T-Cell Responses in Mice. Eur. J. Pharm. Biopharm. 2014, 88, 310-315.

(36) Widera, G.; Johnson, J.; Kim, L.; Libiran, L.; Nyam, K.; Daddona, P. E.; Cormier, M. Effect of Delivery Parameters on Immunization to Ovalbumin Following Intracutaneous Administration by a Coated Microneedle Array Patch System. Vaccine 2006, 24, $1653-1664$

(37) Kumar, A.; Li, X.; Sandoval, M. A.; Rodriguez, B. L.; Sloat, B. R.; Cui, Z. Permeation of Antigen Protein-Conjugated Nanoparticles and Live Bacteria Through Microneedle-Treated Mouse Skin. Int. J. Nanomed. 2011, 6, 1253-1264.

(38) Yang, Z.; Chen, A.; Sun, H.; Ye, Y.; Fang, W. Ginsenoside Rd elicits Th1 and Th2 immune responses to ovalbumin in mice. Vaccine 2007, 25, 161-169. 